\title{
Increasing Athlete Knowledge of Mental Health and Intentions to Seek Help: The State of Mind Ireland (SOMI) Pilot Program
}

\author{
Gavin Breslin \\ Ulster University, Newtownabbey and Ulster University, Derry \\ Tandy Haughey \\ Ulster University, Newtownabbey \\ PLaura Caulfield \\ Bath Spa University \\ Wesley O'Brien \\ University College Cork \\ Alexa Robertson \\ Ulster University, Newtownabbey
}

\section{Martin Lawlor \\ Health Service Executive, South Cork}

\begin{abstract}
The present study had three aims, to determine: (a) whether providing a curriculum-based mental health awareness program to athletes increased knowledge of mental health and intentions to offer support; (b) whether the program increased resilience and well-being compared to a control group; and (c) the feasibility of the program. A total of 100 participants $\left(M_{\mathrm{age}}=20.78 ; S D=2.91\right.$; male $\left.=59\right)$ either attended the program or were part of a control group. Participants completed questionnaires pre-, post-, and 3-months post intervention, although there was a low participant return rate for the 3-month follow-up $(n=15)$. Participants were invited to take part in a focus group to explore program relevance. Knowledge of mental health and intentions to offer support increased for the intervention group, compared to the control. The program with some modification could be integrated into university sport courses to promote mental health awareness.
\end{abstract}

Keywords: anxiety, behavior change, health, resilience, sport, well-being

Breslin, Haughey, and Robertson are with the Sport and Exercise Sciences Research Institute, Ulster University, Newtownabbey, Northern Ireland. Breslin is also with The Bamford Centre for Mental Health and Wellbeing, Ulster University, Derry, Northern Ireland. O'Brien is with the School of Education, Sports Studies and Physical Education Department, University College Cork, Cork, Ireland. Caulfield is with the College of Liberal Arts, Bath Spa University, Bath, United Kingdom. Lawlor is with the Health Service Executive, South Cork, Ireland. Address author correspondence to Gavin 
Mental health is defined as "a state of well-being in which every individual realizes his or her own potential, can cope with the normal stresses of life, can work productively and fruitfully, and is able to make a contribution to her or his community" (World Health Organization; WHO, 2014). Mental health problems are one of the main causes of disease burden, with major depression being the second leading cause of disability and a contributor to suicide and heart disease worldwide (Whiteford et al., 2013). Globally an estimated 350 million people are affected by depression, 60 million by bipolar affective disorder, and 21 million by schizophrenia/other psychoses (WHO, 2016a, 2016b).

There is a paucity of high quality research on student mental health and well-being, with a reliance in many cases on cross-sectional surveys. From these surveys, a significant proportion (more than 1 in 4 ) in the United Kingdom are experiencing clinically recognizable mental illness (Bewick, Gill, Mulhearn, Barkham, \& Hill, 2008), and nearly 8 in 10 indicated that they experienced mental health difficulties over the previous year (NUS services Ltd, 2013). According to Hunt and Eisenberg (2010), within the US, $17 \%$ of students screened positively for depression, and $10 \%$ for an anxiety disorder (panic or generalized anxiety disorder). Drum et al.'s (2009) study of 26,000 students from 70 colleges and universities, also in the US, revealed $6 \%$ of undergraduate students reported having seriously considered suicide in the previous 12 months.

The prevalence of diagnosable psychiatric disorders in athletes ranges from $4 \%$ to $68 \%$ (see Elbe \& Jensen, 2016; Nixdorf, Frank, \& Beckmann, 2016). The variation in reported prevalence is an ongoing debate (Bär \& Markser, 2013; Rice et al., 2016). What is not debated is that prevalence rates of mental disorder in young people and adolescents (aged 16-34) is high at 25-26\% (Gulliver, Griffiths, \& Christensen, 2012; Headstrong, 2012), which is a prominent age for competitive sport participation.

The further understanding of student athlete mental health support is valued, considering athletes have been neglected when it comes to the provision of mental health support services (Hughes \& Leavey, 2012). Neglect in the provision of this support has been attributed in part to the perception that athletes are not at the same risk of developing a mental health problem. Hughes and Leavey (2012) have suggested this is because athletes benefit from the protective effects of exercise and perceived higher levels of resilience. This is not the case. Recent evidence has shown athletes are at risk, if not more at risk, at certain times in their careers to: (a) developing mental health and (b) substance misuse problems, compared to the general population (Rice et al., 2016).

Help-seeking within the athlete population is low, which replicates what currently occurs in the general population. Putukian (2015) attributes low willingness to seek treatment to a view that seeking counselling is a form of weakness. For athletes, to display weakness goes against what competitive sport culture fosters, which is mental toughness (Bauman, 2016). While young people generally do not seek professional help (Gulliver, 2012), university students, have expressed their willingness to seek help from on-campus supports (Karwig, Chambers, \& Murphy, 2015). University students represent a high-risk group (Dooley \& Fitzgerald, 2012) requiring bespoke mental health interventions (Karwig et al., 2015). This period of transition in education from school to university represents a significant time for students (Thomas, 2012). A suggested strategy to improve 
levels of help-seeking for mental health problems is to increase levels of mental health knowledge (Chambers, Murphy, \& Keeley, 2015; Gulliver, Griffiths, \& Christensen, 2010; Jorm, 2012). This includes knowledge of psychological difficulties, which aid their recognition, management and prevention and are critical for high performing athletes in third level education who are part of this high risk group (Rice et al., 2016).

Recent attempts have been made to better understand how to support athletes. A systematic review was conducted by Rice et al. (2016) on the incidence and nature of mental health problems among elite athletes. The authors reviewed sixty studies and concluded that few studies were well reported (25\%), many lacked methodological rigor, and few offered useful interventions. As their review focused on elite athletes only, potential interventions for non-elite athletes in university or club settings, is recommended. In response to the uncertainties of whether mental health awareness programs in sport are effective, a systematic review concluded that programs delivered to athletes have been effective, but caution was advised on the quality of the research designs used to evaluate interventions (Breslin, Shannon, Haughey, Donnelly, \& Leavey, under review). In addition to studies included within the Breslin et al. review iit as been shown that increasing mental health awareness can improve confidence m providing support to someone with a mental health problem (Sebbens, Hassmén, Crisp, \& Wensley, 2016). A study undertaken by the Football Association of England found that using high profile "player ambassadors" had a positive effect on improving health-related behaviors (Mind, 2014).

Enhancing mental health knowledge has become a goal of national mental health policy in Ireland, the United Kingdom (UK), and Australia (Department of Children and Youth Affairs, 2014; Government Office for Science UK, 2008; Australian Department of Health and Ageing, 2009), and sport settings can have a positive role to play in this enhancement of knowledge. Programs using sport, specifically State of Mind, have been nominated as part of the UK's National Suicide Prevention Strategy (Mind, 2014), with the view that harnessing the power of sport through existing social networks (i.e., governing bodies for sport and sport club structures), can promote positive mental health among athletes, fans, and their wider communities. It remains undetermined whether the UK's National Suicide Prevention Strategy is to include university students involved in sport, but would be surprising if not given the large number of university athletes.

In the current study, the State of Mind Ireland (SOMI) program (Lawlor, Rae, $\&$ Kelly, 2015) is a response to the need to do more in university sport settings to enhance mental health awareness. The original State of Mind program was established in England in 2011, with the goal of improving the mental health, well-being, and working life of sports players and their communities mainly in rugby league. To date, no evaluation of the official program has been conducted. The current pilot study tested the effects of providing SOMI, to student undergraduate athletes (aged over 18) to increase their knowledge of mental health, engagement with those with mental health problems, and intentions to seek help, as well as to improve resilience (ability to bounce back from adversity) and wellbeing. Three directional hypotheses were assessed: (a) undergraduate student athletes who received the SOMI mental health and awareness intervention will be significantly more knowledgeable of mental health at follow-up than those in the 
control group; (b) those who receive the intervention will be significantly more likely to engage and offer support to someone with a mental health problem at follow-up than those in the control group; and (c) those who receive the intervention will be significantly more likely to score higher in resilience and well-being at follow up than those in the control group. Finally, as this was a pilot study, we aimed to assess the feasibility of the program. To do this, participants were invited to a focus group immediately after the SOMI program to determine whether participant expectations were met regarding the training, whether the training met their needs, whether the training enhanced their knowledge of mental health, and to establish what could be added to the content of SOMI to enhance the program.

\section{Method}

\section{Participants}

One hundred and forty-two student athletes were invited to take part in the study, of which 100 volunteered and attended (59 male, 41 female; mean age $=20.78 ; S D=$ 2.91). Athletes represented 26 sports (see Figure 1), with the highest participation in soccer $(21 \%)$, followed by Gaelic football (i.e., an Irish team-based sport) $(16 \%)$, rugby (10\%), hockey (7\%), netball (5\%), and golf (4\%). Ethical approval was granted by the leading institution's Research Ethics Filter Committee. All participants provided informed consent prior to the study commencing.

\section{Design}

A between (Group) and within group (Time) design was adopted. The between groups factor had two levels: intervention and control. The intervention group

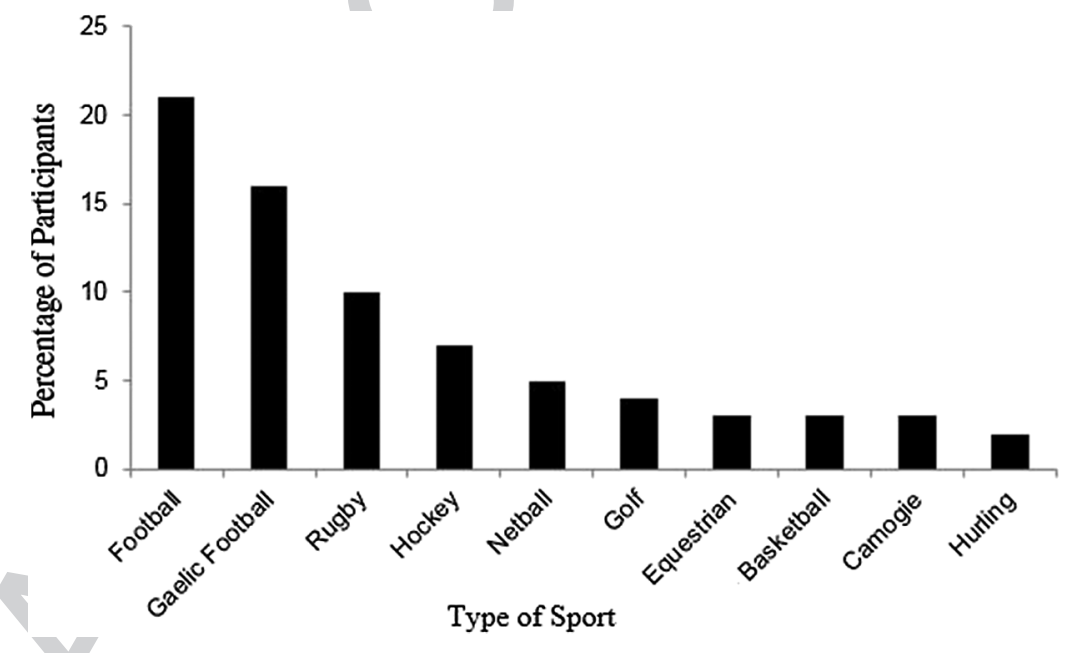

Figure 1 - The prevalence of sport participation among the participants. 
received a multicomponent mental health awareness program $\left(n=56, M_{\text {age }}=\right.$ $19.46, S D=2.11$ ), while a control group received a seminar on an unrelated topic on child physical health, matched for time $\left(n=44, M_{\mathrm{age}}=22.45, S D=2.94\right)$. The within groups factor time, had three levels, baseline, post program, and then a 3-month follow-up. As only 15 participants ( $n=8$ intervention; $n=7$ control) returned questionnaires at 3-month follow-up, only data for pre- and post- program time points were included in parametric statistical analyses.

\section{SOMI: Multi-Component Mental Health and Well-Being Program}

SOMI (Lawlor et al., 2015), is an experiential and skill-enhancing program delivered on a university campus during scheduled class time. The session content and delivery promote mental health, using a more approachable term "mental fitness," which includes experiential group learning (including a resilience case study delivered via video and examples of athletes who, despite being in a "masculine" culture, sought help), group discussion of the World Health Organization's (WHO, 2010) targets for physical activity for health, an introduction to mindfulness practice (Hozel, 2011), and promotion of the "Five Ways to Well-Being - Take 5": 1. Connect (i.e., with family, friends, colleagues and neighbors), 2. Be active (i.e., go for a walk, run, cycle, play a game or dance), 3. Take notice (i.e., be curious and take notice of the surrounding environment and reflect/appreciate what matters), 4. Keep learning (i.e., try something new, rediscover old interests, set a new challenge) and 5. Giving (i.e., do something nice for others, volunteer, be gentle on yourself and others) (Government Office for Science UK, 2008; Rutten et al., 2013). The program was delivered by experienced mental health and well-being tutors. Each tutor received the same training and delivered the standardized program.

\section{Procedure}

All participants were registered on an undergraduate honors degree course in sport a mid-sized university in Ireland. The aims of the research were outlined to participants at the beginning of the session. After providing informed consent, questionnaires were completed prior to and immediately after the training. For the three-month follow-up, questionnaires were posted to the participant's home address. A reminder email was then sent two weeks later to boost response rates. To accommodate 56 participants and to determine if the size of the group was a determinant of effective delivery of the training, the program was delivered by tutors in three separate rooms with different group sizes (small $n=14$; medium $n=18$; and large $n=24$ ). The training lasted 75 minutes. Focus group discussions took place after the training and questionnaire completion.

\section{Outcome Measures}

The following four scales were used:

The Reported and Intended Behaviour Scale (RIBS; Evans-Lacko et al., 2011) is a measure of mental health stigma related behavior, which can be used with the 
general public Items 1-4 address the respondents' exposure to individuals with mental health problems, examining whether they live or work with, or have a neighbor, or close friend, with a mental health problem. Items 5-8 relate to intended behaviors in relation to willingness to live with, work, live nearby or continue a relationship with someone with a mental health problem. Items 5-8 are summed to provide a total score for engaging with someone with a mental health problem. The RIBS has shown good reliability and validity $(\alpha=0.81)$ (Evans-Lacko et al., 2011).

The Mental Health Knowledge Schedule (MAKS) comprises 6 stigma-related mental health knowledge items that assess: help-seeking, recognition, support, employment, treatment and recovery which inquire about knowledge of mental illness conditions (Evans-Lacko et al., 2010). A total score is calculated from summing the six item responses. A further six items on the MAKS assesses knowledge of specific mental illnesses (depression, schizophrenia, bipolar disorder, drug addiction) and often mistaken non-mental illnesses (grief and stress). The MAKS has good reliability and validity $(\alpha=0.55)$ (Evans-Lacko et al., 2010).

The Short Warwick Edinburgh Mental Well-being Scale (SWEMWBS; Tennant et al., 2007) is designed to monitor well-being in the general population. The seven items relate to functioning than to feeling, such as measurement of elements of positive affect, satisfying interpersonal relationships and positive functioning.

The Brief Resilience Scale (BRS; Smith et al., 2008) assesses how individuals deal with challenges throughout life (Windle, Bennett, \& Noyes, 2011). The scale contains six items, such as "I have a hard time making it through stressful events." It is a reliable and valid $(\alpha=0.83)$ measure suitable for use in evaluating programs that seek to promote resilience.

\section{Statistical Analyses}

Separate between group t-tests $(t)$ or Pearson Chi Square $\left(\chi^{2}\right)$ tests were calculated to establish if differences between groups on any of the outcome measures at baseline were present. Separate 2 (Group) $\times 2$ (Time) mixed factors Analysis of Variance (ANOVA) for each outcome variable was calculated to determine main effects and interaction effects $(F)$. To ensure any significant effects were not a result of scores at baseline, separate analysis of covariance (ANCOVA) tests were calculated for outcome measures. Data for the parametric ANOVA test were checked for the following assumptions: the groups were independent from each other, normally distributed, and had equal variance. If Mauchley's test of sphericity was $<.05$, Greenhouse-Geisser was used. Statistical significance was set at $p<.05$. Partial eta squared $\left(\eta_{p}^{2}\right)$ effect size was calculated, providing an indication of what proportion of the variance in the dependent variable is attributable to the intervention. All calculations were performed using the Statistical Package for the Social Sciences (SPSS) Version 19.

\section{Focus Groups}

Seventeen participants took part in three focus groups ( $n=8,7$, and 2 respectively) immediately after the delivery of the SOMI program and after completing the post program questionnaire. Participants responded to the following questions, (a) What 


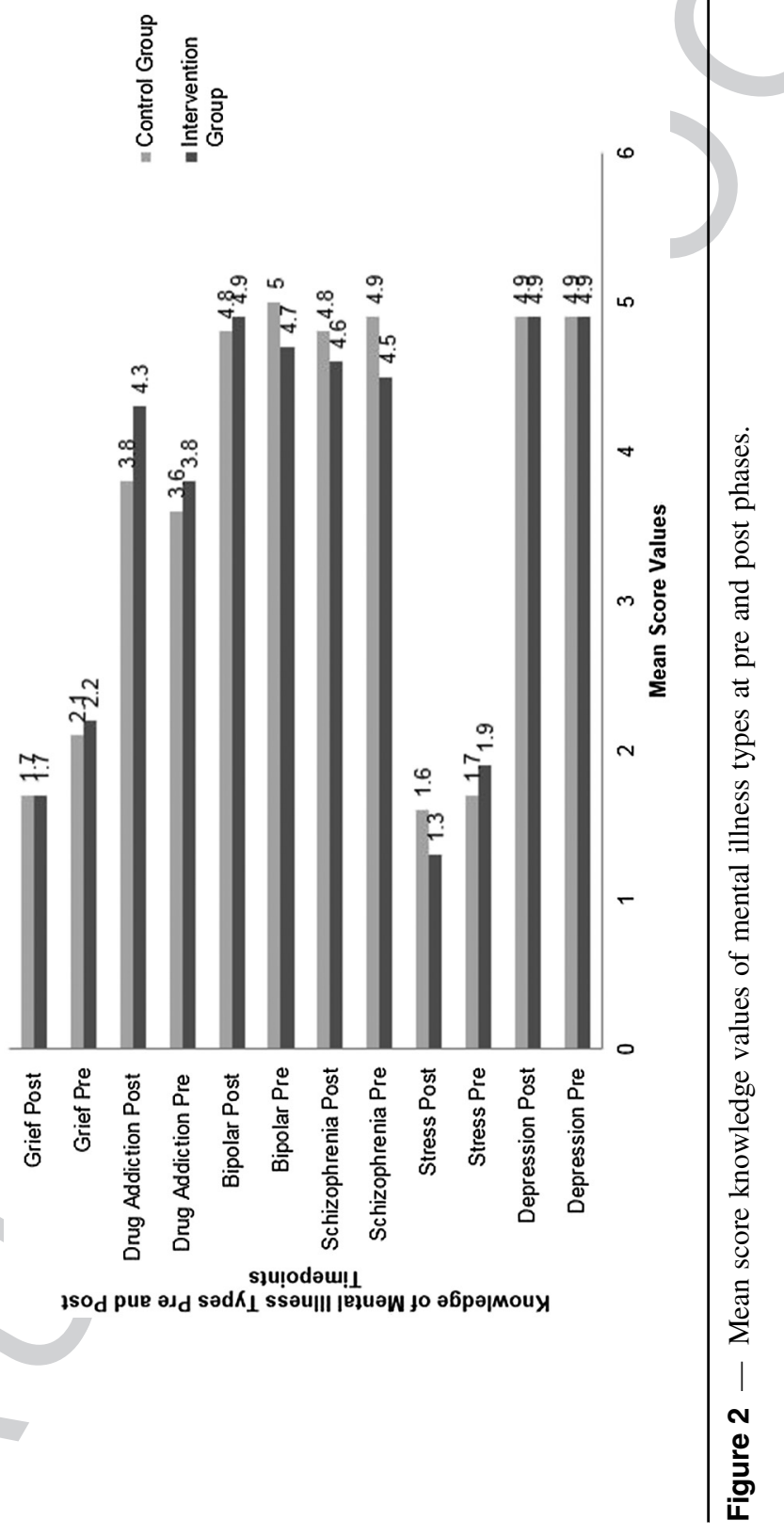

8 
were your expectations from the training? (b) Did the training meet your needs? (c) Did the training add to your knowledge? and finally, (d) What could be added to improve the content of the SOMI program?

Focus group discussions were recorded via a Digital Dictaphone (Phillips Voicetracer, 660), which was transcribed verbatim, and anonymized to ensure confidentiality. As this was a process evaluation, a General Inductive Analysis (GIA) approach was chosen to interpret the data from the focus groups because: (a) it allows researchers to condense raw textual data into a summary format, (b) it allows the establishment of links between research aims and summary findings from the transcripts, and (c) it can be used to inform a framework for interpretation from the views of the participants (Thomas, 2006).

Researcher discussion was utilized early in the investigation to examine and substantiate correct interpretation of the data. Researcher reflexivity through selfawareness and self-reflection remained central during the process to remove bias and reactivity (Bickman \& Rog, 2008). This was achieved through examining and exploring researcher relationship and independence from the participants and maintaining a continuous awareness through all stages of the research process (Conrad, Neumann, Haworth, \& Scott, 1993). Additionally, self-reflection was employed prior to data collection through introspection and exploration of personal bias and motivations for undertaking a study on mental health with student athletes. Journaling helped guide not only the role of the researcher but assisted in the decision making process whereby a critical examination of the purposes of the study and who the study might benefit were reflected upon.

Identifying researcher strengths and weaknesses and understanding investigator influence on participants has been identified as facilitating self-reflexivity (Tracy, 2010). On this basis, as members of the research team were also the participant's university lecturers, the research team made every attempt to encourage the participants to be as open about the program and not to let their relationship with the members of the research team affect their views and opinions of the program. To this end, one of the focus groups was facilitated by a Master's of Science (MSc) student to overcome any potential demand characteristics. Finally, periodic checking of researcher assumptions and memos alongside an examination of their relationship to the research aims was incorporated. Reflective journaling was used to help illuminate unconscious thoughts and bring them into consciousness for examination before analyzing the focus group transcripts (Ortlipp, 2008).

\section{Results}

\section{Group Demographic Check}

The characteristics of the sample at baseline are reported in Table 1. For gender there were no differences between groups. There was no significant difference between the control and the intervention group on the MAKS $(\mathrm{t}=-1.8, \mathrm{df}=94$, $\mathrm{p}>.05)$, RIBS $(\mathrm{t}=-1.94, \mathrm{df}=98, \mathrm{p}>.05)$, and SWEMWBS $(\mathrm{t}=-1.3, \mathrm{df}=95$, $\mathrm{p}>.05)$. There was a borderline significant difference between intervention $(M=3.39, S D=.60)$ and control $(M=3.66, S D=.72)$ for the BRS at baseline, $t=-2.0, \mathrm{df}=96, p=.05$. There was a statistically significant difference in mean age between the intervention $(M=19.46, S D=2.11)$ and control groups 
Table 1 Mean Scores and Standard Deviations for Gender, Age and Outcome Measures at Baseline

\begin{tabular}{lcc}
\hline & Intervention & Control \\
\hline Gender & $\mathrm{M}=36 \mathrm{~F}=20$ & $\mathrm{M}=23 \mathrm{~F}=21$ \\
Age & $19.46(2.11)$ & $22.45(2.93)^{* *}$ \\
MAKS & $21.74(3.0)$ & $22.86(2.96)$ \\
RIBS & $16.57(2.44)$ & $17.57(2.68)$ \\
BRS & $3.39(.60)$ & $3.66(.72)^{*}$ \\
SWEMWBS & $26.49(3.67)$ & $26.36(4.05)$ \\
\hline
\end{tabular}

Note. $\mathrm{p}<.05 ; \mathrm{p}<.001$.

$(M=22.45, S D=2.93) t=5.92, \mathrm{df}=98, p<.001$ at baseline. The students who received the intervention were students in their first year, while those in the control group were third-year students. Student availability was the reason for recruiting year three student athletes as opposed to year one who were all invited to take part. Pre- and post-intervention data are presented for all variables in Table 2.

\section{Mental Health Knowledge}

A total score was computed for knowledge of mental health based on questions 1-6 of the MAKS. The highest score that could have been achieved was 30 . The scores increased from baseline $(M=21.74, S D=3.0)$ to post-intervention $(M=23.4$, $S D=2.2$ ) for the intervention group. To investigate if knowledge changed as a result of the intervention, in comparison to a control group, a $2 \times 2$ mixed factors ANOVA was conducted. As Mauchley's test of sphericity was significant, the Greenhouse-Geisser correction was used. There was a significant interaction effect between Group and Time, $F(1,94)=8.56, p<.01, \eta_{p}^{2}=.08$, with the intervention group exhibiting a greater increase in scores. While both groups demonstrated an increase in knowledge over time, $F(1,94)=15.04, p<.001, \eta_{p}^{2}=.13$, the intervention group exhibited a larger increase compared to control. An ANCOVA was calculated controlling for baseline MAKS mean scores. The difference between groups at follow-up remained statistically significant were the intervention group scored higher on the MAKS, $F(1,93)=62.93, p<.001, \eta_{p}^{2}=.40$.

T) cond component of the MAKS is the knowledge of the types of mental illness $\triangle$ arate Wilcoxon $\mathrm{Z}$ tests were calculated to determine whether the change in knowledge was significant between pre- and post-intervention testing. On follow-up, the intervention participants were more knowledgeable that stress $(Z=-4.48 ; p<.001)$ and grief $(Z=-3.27 ; p<.01)$ were not mental illnesses, indicative of a reduction on the MAKS and an increase in scores for bipolar disorder $(Z=-2.5 ; p<.05)$ and drug addiction $(Z=-3.68 ; p<.001)$ as classified mental illnesses. There were no significant knowledge changes for depression or schizophrenia amongst the intervention group. For the control group, there were no significant changes in knowledge of mental illnesses, except for grief, with scores significantly decreasing indicative that the control group became more aware that grief was not a mental illness $(Z=-3.34 ; p<.01)$. 


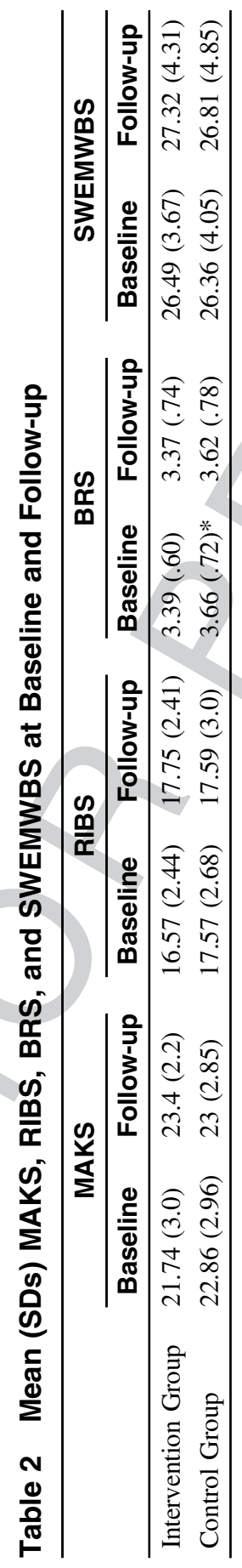

圆 


\section{Intentions to Engage With Someone With a Mental Health Problem}

Questions 5-8 of the RIBS were summed to provide a total score indicative of whether participants would be willing to engage with someone with a mental health problem. The pre-test total score of $16.57(S D=2.4)$ increased to $17.75(S D=2.4)$ after the training for the intervention participants. To investigate if intentions to engage with someone with a mental health problem changed as a result of the intervention, a $2 \times 2$ mixed factors ANOVA with the independent variables of testing session (Time) and for Group (i.e., intervention versus control) was conducted. As Mauchley's test of sphericity was significant, the GreenhouseGeisser correction was used. There was a significant interaction effect between Group and Time, $F(1,98)=9.74, p<.01, \eta_{p}^{2}=.09$, with the intervention group exhibiting a greater increase in scores. While both groups demonstrated an increase in intentions to provide support over time, $F(1,98)=10.52, p<.01, \eta_{p}^{2}=.09$, the intervention group exhibited a larger increase as a result of the training. An ANCOVA was calculated controlling for baseline total RIBS scores, and the difference between groups at follow up remained statistically significant wherein the intervention group scored higher, $F(1,99)=128.58, p<.001, \eta_{p}^{2}=.57$.

\section{Resilience and Well-Being}

For the BRS there was no significant main effect of group $(\mathrm{F}(1,94)=.3 .39, \mathrm{p}=.06$; $\left.\eta_{p}^{2}=.04\right)$, no within group effect $\left(\mathrm{F}(1,94)=.46, p>.05 ; \eta_{p}^{2}=.005\right)$, and no significant interaction effect between time and group $(\mathrm{F}(1,94)=.06,>.05$; $\left.\eta_{p}^{2}=.001\right)$. As there was a borderline statistically significant difference at baseline for BRS (see Table 1), a one-way ANCOVA was calculated that accounted for this potential difference. Despite an adjustment to the mean scores through the ANCOVA, no significant interaction effect was present. For the SWEMWBS, there was no significant main effect of Group, there was a within-group effect wherein both groups increased their scores $\left(\mathrm{F}(1,93)=9.01, p<.05 ; \eta_{p}^{2}=.08\right)$, although this increase was not due to the intervention, as no significant interaction effect was shown between Time and Group.

\section{Focus Group Results}

All participants agreed that the intervention enhanced their knowledge of mental health and well-being. In general, participants recalled the following information: "mental fitness" as a relevant and arguably less stigmatizing term than "mental health," the five actions for improving mental health, and the video content of mental health experiences of an athlete. It was evident that the knowledge and confidence to offer support to a person was increased, with participants stating: "If you do know someone, you at least have more confidence to go to talk to them, and try to get them to talk, you know, simple conversation and stuff like that" and:

Never just brush it aside, whether it be a small problem or a major problem, you can always offer up a hand to someone or point them in the right direction. It doesn't even have to be you personally. 
We're so used to just saying "well, how are you?" We don't listen to them, like they might genuinely say, "hey I'm alright," but there maybe is something going on that you don't know about, and unless you actually dive in and see, you'll never find out.

The term "mental fitness" was used in the program in place of "mental health" and "well-being." It was evident from the participants' views in relation to this terminology that the terms used are important in engaging young people in messages around mental health. Participants said:

Illnesses, kind of like you think, oh, people have illness or disorders. I think it was good the guy mentioned (referring to the trainer), what was it he said, something like "fitness," he said there was another word for it instead of putting that label on it, "mental fitness," which was quite good.

A second participant said: "If you think to being around campus, in terms of student support, that it's not mental health and well-being, it's that fitness aspect of it?" A third participant said:

Yeah, that appeals better, you don't feel as maybe looked at. Coming into this class, if you think "mental health and well-being," people think what's wrong with him? Or you know, if it's "mental fitness" it's more general, but it's more centered, too, you know, without that name (referring to "mental health") kind of attached.'

In relation to the five actions for mental health, there was a positive response from participants with one saying:

Them five steps, that five-a-day thing, it was really good, cause not only will it help you to look out for them things when it's other people, but you can go through the steps yourself so that you're not falling into that category.

The video and delivery of the session were viewed as positive, and timely in the semester, given that examinations were approaching. It was suggested that there may be opportunities for alternative suitable times for delivery of the program, mainly at the beginning of semester one for first-year students. Regarding content and delivery of the program, a participant commented: "I thought that even the video was good, because it was a real life experience, a real life sport, and it probably happens in everybody's sport like." When asked how the program could be delivered in the future, participants said the program could be delivered as it is, and that having SOMI an external organization coming into the university and delivering the session was a strong point for student engagement purposes. One participants said: "I think you should keep them coming in, carrying out the session themselves. You feel a lot more like you should be listening . .., you just appreciate it more." A second participant commented:

And having people that are actually in the job.....so they can give you experiences that they have went through, which makes it more realistic... whereas if somebody had given you a presentation saying yes it's happening, but they have no first time experience, you don't relate to it the same way. 
Finally, a third participant said:

And the way they made it more interactive, like the guy got us to do that wee activity where they get us to try not to think of anything but listen.., that was good to get us involved, and then we kind of, paid attention more maybe, after that.

Participants commented appreciatively on specific content included in the program, which they found impacted upon their learning: "The mindfulness, close your eyes, breathing, clear your mind, stuff that could be used at any class like, you know even if it is in a lecture, you can break a lecture down and do that, you know." Another participant commented, "There's probably more exercises you could do to train your mind and get yourself relaxed; I'm sure there's more tools and tips and stuff, like that." Some participants, however, felt there was too much information covered in the program:

I think if you were trying to fit everything in, it could get pretty heavy, and people would lose interest. So maybe if you have different events and different days, you can have the opportunity to go to. so maybe they have one for how to spot problems, and one for how to deal with.... You have the choice to go to one of them, and you don't have to go to them all.

Although students found the setting for delivery supported them personally, they thought the program could be delivered in other settings, such as their sport clubs, which might be more impactful. Participants recognized the sports club setting within university currently has little if any mental health promotion: "A workshop could be easily done with your sporting team or your club like . . . there's very little of it done."

\section{Discussion}

The aim of the current study was to determine whether providing a mental health awareness program, SOMI, to athletes improved their knowledge of mental health, engagement with those with mental health problems, intentions to provide support to others, and increased their well-being and resilience. The first hypothesis was supported. Knowledge of mental health, and the types of mental illnesses increased in the intervention group more than among the controls. In particular, athlete knowledge of bipolar disorder and drug addiction increased, as did recognition that grief and stress are not mental disorders. Knowledge of depression and schizophrenia did not increase in either the intervention or control group. The lack of an increase relative to these two disorders may reflect an already high level of knowledge. gained from the recent education based public mental health awareness media campaign, which focused on mental disorders and help seeking, which had depression as the central focus (http://www. mindingyourhead.info/). The second hypothesis was also supported, as athletes who received the SOMI intervention were more likely to engage with and offer support to someone with a mental health problem at follow up compared to the control group. 
The findings support previous studies that have increased knowledge of mental health in elite athletes (Rice et al., 2016). Findings also support previous research that has shown an increase in athlete's intention to engage and offer support to someone with a mental health problem as a result of a short mental health awareness program (Breslin, Haughey, Donnelly, Kearney, \& Prentice, 2017). The SOMI intervention has also raised awareness of mental disorders, similar to previous programs (Bapat, Jorm, \& Lawerence, 2009; Sebbens et al., 2016; Van Raalte et al., 2015).

The third hypothesis was not supported. Athletes who received the SOMI program did not demonstrate improvement in well-being or resilience scores postintervention relative to the control group. The lack of improvement may have been due either to the structure and content of the program or to the timing in which measurements were collected post the intervention. In terms of content, the program emphasized mental health awareness and sign-posting those with mental health problems to services, as opposed to providing coping strategies to alleviate mental health problems. To achieve improvements in well-being or resilience, a similar approach to previous programs that have reduced depressive symptoms and anxiety could be considered (Donohue et al., 2013; Donohue et al., 2015; Longshore \& Sachs, 2015). For enhancement of the program, one session is likely not enough to achieve increased well-being or resilience. Therefore, additional time could be required to observe well-being and resilience changes. Data collected 3 months post the intervention was not included in the analysis due to small return from participants. A three-month follow up was conducted, but due to a low return rate, statistical analyses could not be performed on the followup data.

The duration of the SOMI program for university students was perceived as advantageous, and the program had a high level of attendance because it was a scheduled class session, as opposed to an opt-in session. Future mental health awareness courses for delivery to university athletes might implement this model and embed mental health awareness workshop in the curriculum. A short-length program with specific outcomes to facilitate engagement and impact may be more efficient than opt-in programs provided outside the curriculum. A barrier to mental health help-seeking is stigma (Hughes \& Leavey, 2012). Engaging university thletes in discussion around mental health in the classroom and assist them in dentifying the relevance could be important in reducing stigma and associated avoidance. In addition to the scheduling of the class, participants highlighted that having an experienced facilitator was an integral part of the SOMI delivery, and it may influence the attention of those attending.

The term "mental fitness" was used in place of traditionally used terms, such as "mental health" and "illness" that can have negative connotations, or lack relevance to young people. The term "mental fitness" provided an adaptive approach to stressful life events, by potentially normalizing distress, enhancing understanding of mental processes, reframing (improved cognitive flexibility) to enhance mastery skills, and using adversity as an opportunity to learn. Also, the term "mental fitness" may bring new interest to a topic previously associated with stigma and avoidance of help-seeking (Byrne, 2000). The participant's response that using the term "mental fitness" created curiosity that facilitated attendees to speak more freely about the psychological challenges placed on them in their daily 
lives was encouraging. "Mental fitness" may well be relevant for athletes, but it is unclear whether using the term with non-athletes attending university would be beneficial, and additional research is required to address that question.

There were several limitations to the current pilot study, but also lessons learned, with regards to: (a) the fidelity of the program and (b) feasibility of the research. Participants were not randomized into groups, and researchers were prevented from establishing the long-term effects of the program at the threemonth time point due to poor return rate of questionnaires. This return related to the timing of delivery of the intervention and academic year. Students were not in attendance at university at the point 3 of data collection, to rectify this issue other means of gathering data could be considered to assist with compliance. attrition. Also, while participants showed an increase in the desire to engage with someone who has mental health problems and the intention or potential to offer support, it was not possible to determine whether the training could actually lead to an athlete supporting someone. Further follow-up with participants would be required to examine post-intervention behavior. Finally, given that the effect sizes for some of the changes were small, further exploration of the content of the program over longer periods could be evaluated.

Future research and program development could also be based on a psychological behavior change theory. This proposed enhancement of the program may further augment the intention and help-seeking behavior change components of the program. To aid this, guidelines are available from the Medical Research Council (2000). It is recommended that psychological theories such as self-determination theory (Deci \& Ryan, 2002), or the theory of planned behavior (Ajzen, 1985) be considered in developing and evaluating interventions, and providing more information on the motivations for behavior change. The choice of theory should be determined with the planned outcomes of the intervention in mind (see Michie et al., 2015, regarding development of methods and measures for reporting behavior change).

In conclusion, a short 75-minute student athlete mental health awareness program when delivered by experienced facilitators can increase knowledge of mental health, including knowledge of mental disorders beyond that of a control group. The SOMI program can also increase athlete intentions to engage and offer help/support to someone with a mental health problem. Mental health and wellbeing in sport courses such as SOMI could be considered for inclusion in the development of coach education, player welfare and safe guarding athletes while enrolled in university. Further research is required into what components of the interventions could be modified to improve resilience and well-being.

\section{References}

Ajzen, I. (1985). From intentions to actions: A theory of planned behavior. In J. Kuhl, and J. Beckmann (Eds.), Action-control: From cognition to behavior (pp. 11-39). Heidelberg, Germany: Springer.

Australian Department of Health and Ageing. (2009). Fourth National Mental Health Plan: An agenda for collaborative government action in mental health 2009-2014. Canberra, Australia: Commonwealth of Australia. 
Bapat, S., Jorm, A.F., \& Lawrence, K. (2009). Evaluation of a mental health literacy training program for junior sporting clubs. Psychiatry, 17, 475-479. doi:10.1080/ 10398560902964586

Bär, K.-J., Markser, V.Z. (2013). Sport specificity of mental disorders: The issue of sport psychiatry. European Archives of Psychiatry Clinical Neuroscience, 263(2):205-210. doi:10.1007/s00406-013-0458-4

Bauman, N.J. (2016). The stigma of mental health in athletes: Are mental toughness and mental health seen as contradictory in elite sport? British Journal of Sports Medicine, 50(3), 135-136. PubMed doi:10.1136/bjsports-2015-095570

Bewick, B.M., Gill, J., Mulhearn, B., Barkham, M., \& Hill, A.J. (2008). Using electronic surveying to assess psychological distress within the UK student population: A multisite pilot investigation. E-Journal of Applied Psychology, 4(2), 1-5. doi:10.7790/ejap. v4i2.120

Bickman, L., \& Rog, D.J. (2008). Handbook of applied social research methods. Thousand Oaks, CA: Sage Publications.

Breslin, G., Haughey, T., Donnelly, P., Kearney, C., \& Prentice, G. (2017). Promoting mental health awareness in sport clubs. Journal of Public Mental Health, 16(2), 55-62. doi:10.1108/JPMH-08-2016-0040

Breslin, G., Shannon, S., Haughey, T.J., Donnelly, P., \& Leavey, G. (under review). A systematic review of interventions to increase awareness of mental health and wellbeing in athletes and coaches. International Sport and Exercise Psychology Review.

Byrne, P. (2000). Stigma of mental illness and ways of diminishing it. Advances in Psychiatric Treatment, 6, 65-72. doi:10.1192/apt.6.1.65

Chambers, D., Murphy, F., \& Keeley, H.S., (2015). All of us? An exploration of the concept of mental health literacy based on young people's responses to fictional mental health vignettes. Journal of Psychological Medicine, 82, 1-8.

Conra, C., Neumann, A., Haworth, J.G., \& Scott, P. (1993). Qualitative research in higher education: Experiencing alternative perspective and approaches. Needham Heights, MA: Ginn Press.

Peci, E., \& Ryan, R. (Eds.). (2002). Handbook of self-setermination pesearch (1st ed.). Rochester, NY: University of Rochester Press.

Department of Children and Youth Affairs. (2014). Better outcomes, brighter futures. The national policy framework for children and young people 2014-2020. Dublin, Ireland: Government Publications.

Donohue, B., Chow, G.M., Pitts, M., Loughran, T., Schubert, K.N., Gavrilova, Y., \& Allen, D.N. (2015). Piloting a family-supported approach to concurrently optimize mental health and sport performance in athletes. Clinical Case Studies, 14(3) 159-177. doi:10. $1177 / 1534650114548311$

Donohue, B., Pitts, M., Gavrilova, Y., Ayarza, A., \& Cintron, K.I. (2013). A culturally sensitive approach to treating substance abuse in athletes using evidence-supported methods. Journal of Clinical Sport Psychology, 7(2), 98-119. doi:10.1123/jcsp.7.2.98

Dooley, B., \& Fitzgerald, A. (2012). My world survey. National survey of youth mental health in Ireland. Dublin, Ireland: University College Dublin and Headstrong.

Drum, D.J., Brownson, C., \& Denmark, A.B. (2009). New data on the nature of suicidal crises in college students: Shifting the paradigm. Professional Psychological Research Practice, 40, 213-222. doi:10.1037/a0014465

Elbe, A., \& Jensen, J.S. (2016). Commentary: Comparison of athletes' proneness to depressive symptoms in individual and team sports: Research on psychological mediators in junior elite athletes. Frontiers in Psychology, 7:1782. PubMed doi:10. 3389/fpsyg. 2016.01782

Evans-Lacko, S., Little, K., Meltzer, H., Rose, D., Rhydderch, D., Henderson, C., \& Thornicroft, G. (2010). Development and Psychometric Properties of the Mental 
Health Knowledge Schedule (MAKS). Canadian Journal of Psychiatry, 55, 440-448. PubMed. doi:10.1177/070674371005500707

Evans-Lacko, S., Rose, D., Little, K., Flach, C., Rhydderch, D., Henderson, C., \& Thornicroft, G. (2011). Development and psychometric properties of the Reported and Intended Behaviour Scale (RIBS): A stigma-related behaviour measure. Epidemiology and Psychiatric Sciences, 20, 263-271. PubMed. doi:10.1017/S2045796 011000308

Government Office for Science, UK. (2008). Mental capital and well-being: making the most of ourselves in the 21st century. London: The Government Office for Science.

Gulliver, A., Griffiths, K.M., \& Christensen, H. (2010). Perceived barriers and facilitators to mental health help-seeking in young people: A systematic review. BMC Psychiatry, 10, 113. PubMed. doi:10.1186/1471-244X-10-113

Gulliver, A., Griffiths, K.M., \& Christensen, H. (2012). Barriers and facilitators to mental health help-seeking for young elite athletes: A qualitative study. BMC Psychiatry, 12, 157. PubMed doi:10.1186/1471-244X-12-157

Headstrong. (2012). Somewhere to turn to, Someone to talk to. Retrieved from http://archive .headstrong.ie/wp-content/uploads/2014/07/Headstrong-Annual-Report-2012.pdf

Hughes, L., \& Leavey, G. (2012). Setting the bar: Athletes and vulnerability to mental illness. British Journal of Psychiatry, 200(2), 95-96. PubMed. doi:10.1192/bjp.bp.111. 095976

Hunt, J., \& Eisenberg, D. (2010). Mental health problems and help-seeking behavior among college students. Journal of Adolescent Health, 46(1), 3-10. PubMed. doi:10.1016/ j.jadohealth.2009.08.008

Jorm, A. (2012). Mental health literacy: Empowering the community to take action for better health. American Psychologist, 67, 231-243. PubMed. doi:10.1037/a0025957

Karwig, G., Chambers, D., \& Murphy, F. (2015). Reaching Out in College: Help-Seeking at Third Level in Ireland. Dublin, Ireland: ReachOut.

Lawlor, M., Rae, M., Kelly, N., \& Moriarty, P. (2015). State of mind Ireland: Towards a skills for life passport. Proceedings of the CRSI Conference. Retrieved from www. stateofmindireland.com/crsi/resources

Longshore, K., \& Sachs, M. (2015). Mindfulness training for coaches: A mixed-method exploratory study. Journal of Clinical Sport Psychology, 9(2), 116-137. doi:10.1123/ jcsp.2014-0038

Medical Research Council. (2000). A framework for the development and evaluation of $R C T$ s for complex interventions to improve health. London, United Kingdom: Medical Research Council.

Q10 Mind. (2014). Performance matters in elite sport.

Nixdorf, I., Frank, R., \& Beckmann, J. (2016). Comparison of athletes' proneness to depressive symptoms in individual and team sports: Research on psychological mediators in junior elite athletes. Frontiers in Psychology, 7, 893. PubMed doi:10. 3389/fpsyg.2016.00893

NUS Services Ltd. (2013). Mental distress survey overview. Retrieved from http://www. nus.org.uk/Global/Campaigns/20130517\%20Mental\%20Distress\%20Survey\%20\%20 Overview.pdf

Ortlipp, M. (2008). Keeping and using reflective journals in the qualitative research process. The Qualitative Report, 13(4), 695-705.

Putukian, M. (2015). The psychological response to injury in student athletes: a narrative review with a focus on mental health. British Journal of Sports Medicine, 50(3), 145-148. PubMed doi:10.1136/bjsports-2015-095586

Rice, S.M., Purcell, R., De Silva, S., Mawren, D., McGorry, P.D., \& Parker, A.G. (2016). The mental health of elite athletes: A narrative systematic review. Sports Medicine, 46(9), 1333-1353. PubMed. doi:10.1007/s40279-016-0492-2 
Rutten, B.P.F., Hammels, C., Geschwind, N., Menne-Lothmann, C., Pishva, E., ... Wichers, M. (2013). Resilience in mental health: Linking psychological and neurobiological perspectives. Acta Psychiatrica Scandinavia, 128, 3-20. doi:10.1111/acps. 12095

Sebbens, J., Hassmén, P., Crisp, D., \& Wensley, K. (2016). Mental health in sport (MHS): Improving the early intervention knowledge and confidence of elite sport staff. Frontiers in Psychology, 24(7), 911. doi:10.3389/fpsyg.2016.00911

Smith, B.W., Dalen, J., Wiggins, K., Tooley, E., Christopher, P., \& Bernard, J. (2008). The brief resilience scale: assessing the ability to bounce back. International Journal of Behavioral Medicine, 15(3), 194-200. PubMed. doi:10.1080/10705500802222972

Tennant, R., Hiller, L., Fishwick, R., Platt, S., Joseph, S., Weich, S, . . Stewart-Brown, S. (2007). The Warwick-Edinburgh Mental Well-being Scale (WEMWBS): development and UK validation. Health and Quality of Life Outcomes, 5, 63. PubMed. doi:10.1186/ $1477-7525-5-63$

Thomas, D.R. (2006). A general inductive approach for analyzing qualitative evaluation Data. American Journal of Evaluation, 27(2), 237-246. doi:10.1177/1098214 005283748

Thomas, L. (2012). Building student engagement and belonging in Higher Education at a time of change: final report from the What Works? Student Retention \& Success program. Retrieved from https://www.heacademy.ac.uk/system/files/what_works_ final_report_0.pdf

Tracy, S.J. (2010). Qualitative quality: Eight "big-tent" criteria for excellent qualitative research. Qualitative Inquiry, 16(10), 837-851. doi:10.1177/1077800410383121

Van Raalte, J.L., Cornelius, A.E., Andrews, S., Diehl, N.S., \& Brewer, B.W. (2015). Mental health referral for student-athletes: Web-based education and training. Journal of Clinical Sport Psychology, 9, 197-212. doi:10.1123/jcsp.2015-0011

Whiteford, H.A., Degenhardt, L., Rehm, J., Baxter, A.J., Ferrari, A.J., Erskine, H.E., \& Johns, N. (2013). Global burden of disease attributable to mental and substance use disorders: Findings from the global burden of disease study 2010. The Lancet, 382(9904), 1575-1586. doi:10.1016/S0140-6736(13)61611-6

Windle, G., Bennett, K.M., \& Noyes, J. (2011). A methodological review of resilience measurement scales. Health and Quality of Life Outcomes, 9, 8-18. doi:10.1186/14777525-9-8

World Health Organization. (2010). Global recommendations on physical activity for health. Geneva, Switzerland: World Health Organization.

World Health Organization. (2014). Mental health: A state of well-being. Geneva, Switzerland: World Health Organization.

World Health Organization. (2016a). Media centre, Depression Fact Sheet. Geneva, Switzerland: World Health Organization. Retrieved from http://www.who.int/ mediacentre/factsheets/fs369/en/

World Health Organization. (2016b). Media centre, Mental Disorders Fact Sheet. Geneva, Switzerland: World Health Organization. 


\section{Queries}

Q1. Please ensure author information is listed correctly here and within the byline.

Q2. Please add in text citation for Figure 2.

Q3. Please provide the complete reference details for "Hozel (2011)" to be included in the reference list.

Q4. Please label the footnote with designators "*” and "**” in Table 1.

Q5. Please provide significance of the footnote "*” cited in Table 2.

Q6. Reference "Hughes \& Leavey (2015)" cited has been changed to "Hughes \& Leavey (2012)" as per the reference list. Please verify.

Q7. Reference "Deci \& Ryan (2000)" cited has been changed to "Deci \& Ryan (2002)" as per the reference list. Please verify.

Q8. Reference "Ajzen (1984)" cited has been changed to "Ajzen (1985)" as per the reference list. Please verify.

Q9. Please provide the complete reference details for "Michie et al. (2015)" to be included in the reference list.

Q10. Please provide complete details for reference "Mind (2014)." 